\title{
Venício Lima: em defesa da democratização dos meios de comunicação
}

\section{Cláudia Nonato}

Jornalista, doutoranda em Ciências da Comunicação na ECA-USP, pesquisadora do Centro de Pesquisa em Comunicação e Trabalho (CPCT) e editora executiva da revista Comunicação \& Educação

E-mail: claudia.nonato@usp.br

Resumo: Venício A. de Lima é um estudioso de mídia e de política, além de defensor da liberdade de expressão e da democratização da comunicação no país. Nesta entrevista, o professor, aposentado como titular de Ciência Política e Comunicação da UnB, autor de diversos livros e articulista permanente dos sites Observatório da Imprensa e Carta Maior, além da revista Teoria em Debate, entre outros, fala de sua formação acadêmica, de sua visão da contemporaneidade a partir da introdução das novas tecnologias, e faz uma reflexão sobre a Lei de Meios argentina. Também mostra os problemas causados pela concentração da mídia e pela falta de uma regulação dos meios de comunicação no Brasil.

Palavras-chave: comunicação e política; liberdade de expressão; democratização da mídia; regulação da mídia; lei de meios.
Abstract: Venício A. de Lima is a media and politics researcher, and also a defender of freedom of speech and of the democratization of communication in Brazil. In this interview, the retired professor of Political Science and Communication at UnB, author of many books and columnist of the websites Observatório da Imprensa e Carta Maior and of the magazine Teoria em debate, among others, talks about his academic education, his perspective on the contemporary world with the emergence of new technologies and the Medium Law from Argentina. Also, he shows the problems caused by the concentration of media and by the lack of regulation of the communication media in Brazil.

Keywords: communication and politics; freedom of speech; media democratization; media regulation; media law.

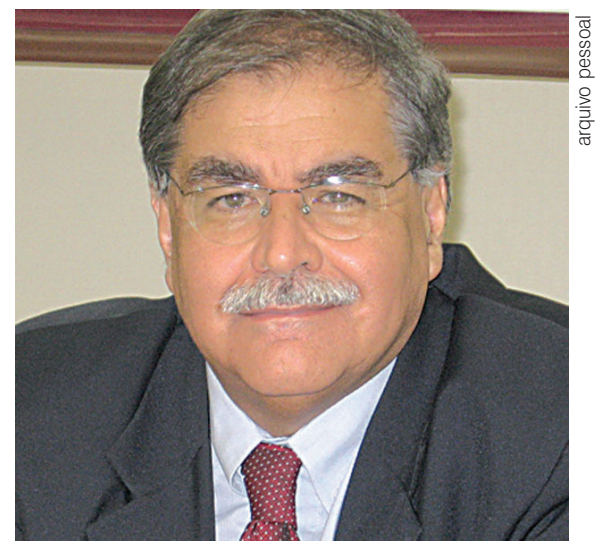


1. LIMA, Venício A. de. Comunicação e cultura: as ideias de Paulo Freire. 2. ed. rev. Brasília: Editora da Universidade de Brasília/ Fundação Perseu Abramo, 2011.

2. O movimento que formou o grupo Ação Popular surgiu em 1962, após um congresso da esquerda católica. Lutava pelo socialismo humanista e foi composto, principalmente, de lideranças estudantis da época, tais como Betinho, Jair Ferreira de Sá, José Serra, Vinícius Caldeira Brant, Aldo Arantes, Haroldo Lima, Duarte Lago Pacheco e outros, contando ainda com a participação de lideranças camponesas e operárias.
Sociólogo por formação, o professor, natural de Sabará, Minas Gerais, iniciou seus estudos na Universidade Federal de Minas Gerais, ainda nos anos 1960, e completou a carreira acadêmica nos Estados Unidos, com mestrado, doutorado e pós-doutorado pela Universidade de Illinois e também pela Universidade de Miami. De volta ao Brasil, foi titular de Ciência Política e Comunicação da Universidade de Brasília, atuando como fundador e primeiro coordenador do Núcleo de Estudos sobre Mídia e Política da UnB. Além disso, foi professor convidado de diversas universidades no Brasil, Estados Unidos e Cuba. Embora hoje esteja aposentado da Universidade de Brasília, aos 68 anos, o professor mostra-se extremamente produtivo e atento às questões da contemporaneidade. Em seus livros e artigos publicados como articulista nos sites Observatório da Imprensa e Carta Maior, por exemplo, é possível perceber que Lima é um incansável defensor da liberdade de expressão e da democratização dos meios de comunicação no Brasil. Ele nos recebeu em Brasília, onde mora, e nos falou sobre os movimentos católicos e políticos do qual fez parte ainda na adolescência, da relação com Paulo Freire, além de mostrar a importância da regulação e também da descentralização da mídia no Brasil.

Comunicação Ẽ Educação: A sua tese de doutorado, nos Estados Unidos, foi sobre as ideias do Paulo Freire em Comunicação e Cultura. Qual a importância de Paulo Freire para a sua formação? Por que a escolha por esse tema?

Venício Lima: Essa tese virou um livro que, inclusive, foi reeditado trinta anos depois ${ }^{1}$. E tem muito a ver com a minha biografia. Eu fiz 18 anos em 1963; estudei em colégio interno e descobri a política na minha adolescência, num período em que o país estava muito conturbado. Havia uma efervescência muito grande da juventude, de mobilização popular, e eu naquela época - como estudava no Colégio Arquidiocesano de Ouro Preto, de muita tradição - entrei para a JEC (Juventude Estudantil Católica). A minha formação política e humana foi dada nesse ambiente, eu virei um militante, tinha toda aquela coisa da esquerda católica, foi a época de pessoas como Betinho, e a formação da Ação Popular². E Paulo Freire era uma referência, não só política, porque se pensava nele como um sujeito capaz de liderar um processo que tornava as pessoas, em muito pouco tempo, alfabetizadas, o que significava no processo eleitoral a possibilidade de eleger candidatos. Miguel Arraes era a liderança política da época. No final de 1963, eu saí de Ouro Preto e fui para Belo Horizonte para fazer Sociologia e Política; meus pais queriam que eu fosse engenheiro, por isso eu estava em Ouro Preto, mas esse curso de Sociologia e Política da antiga FACE, Faculdade de Ciências Econômicas, da UFMG, era o lugar onde tinham estudado essas pessoas: Betinho, Edmar Bacha, Vinícius Caldeira Brant, Vilmar Farias e muitos outros. $\mathrm{Eu}$ fiz vestibular para esse curso e lá me envolvi com um pessoal que usava o método Paulo Freire em favelas. E foi assim, na militância, na política estudantil, que conheci Paulo Freire. Muitos anos depois eu tinha que escolher um tema de tese. O instituto em que estudei - o Institute of Communications Research da University of Illinois, em Urbana, - é muito tradicional, fundado em 1947, acho que foi o primeiro centro de pesquisa universitário em Comunicação dos Estados 
Unidos. O primeiro diretor lá foi o Wilbur Schramm [1907-1987], que depois foi para Stanford, pioneiro do estudo da Comunicação no país. Eu trabalhava com professores muito abertos; minha ideia inicial era fazer uma comparação entre Paulo Freire e Habermas, mas eu não sabia alemão, era muito complicado. Naquela época, nem em inglês se tinha, por exemplo, o livro Mudança estrutural da esfera pública. Ele foi publicado primeiro em português, aliás. Então eu desisti do Habermas e me concentrei no Paulo Freire. Ele estava no exílio, nós nos correspondemos, e o conheci pessoalmente em 1978, quando ele foi aos Estados Unidos para um seminário em Michigan. E foi interessante, porque ele ficou dois dias em Michigan, eu combinei com ele, fui pra lá, nós conversamos por dois dias, é verdade! Mas é porque ele gostava de conversar, estava no campus da universidade, um lugar bonito, agradável, dava seminários de manhã e de tarde eu ficava conversando com ele. Conheci a Elza, primeira esposa dele, depois fiquei amigo, de ir na casa, me hospedar na casa dele. Foi assim. Naquela época, 1976-78, havia muita coisa sobre Paulo Freire, sobretudo fora do Brasil, mas não tinha nada na área de Comunicação. Havia aqui na UnB, quando começou o mestrado, em 1974, um professor paraguaio que morava no Brasil, Juan Diaz Bordenave [1926-2012], que falava no Paulo Freire na perspectiva da extensão rural, por causa do Extensão ou Comunicação? [original 1969]. E então apresentei um projeto de tese nos Estados Unidos, que era para fazer uma leitura do Paulo Freire que não existia, do ponto de vista da discussão sobre a Comunicação, e eles toparam. Tem muito a ver também com o ambiente do lugar onde eu estava, porque o professor mais importante lá, James Carey - que ninguém conhece no Brasil, não tem praticamente nada traduzido dele - era o personagem mais importante dos Estudos Culturais americanos. E tinha uma contraposição entre os Estudos Culturais americanos e os Estudos Culturais ingleses. A versão inglesa tinha matriz marxista, e a americana era de um liberalismo, digamos assim, progressista, da Escola de Chicago. Eu estava muito envolvido naquilo e achava que o Paulo Freire era uma espécie de ponte para uma eventual construção de uma perspectiva cultural para observar a Comunicação na América Latina, no Brasil. Eu fiz essa leitura do Paulo Freire do ponto de vista da Comunicação, e foi um acerto de contas com a minha própria biografia. Porque para entender Paulo Freire você tinha que entender os movimentos cristãos da época, a esquerda católica, o contexto do populismo, a chamada (por ele) "emergência das massas populares". E eu tinha um comitê de tese que era absolutamente receptivo, ninguém imagina que podia ter isso numa universidade no centro-oeste americano, no meio de milho, soja e trigo. $\mathrm{O}$ chair do meu comitê era o Thomas Guback, um dos nomes mais importantes da Economia Política da Comunicação, ele foi aluno do Herbert Schiller, na mesma tradição que vem do Dallas Smythe, e ele foi o terceiro dessa linhagem. Era marxista, na sala dele tinha um retrato de Lênin. O meu orientador mesmo era um calvinista, um homem religioso, que vinha da área de estudos da Linguística, humanista, estudioso de ética, o Clifford Christians. E era um sujeito entusiasmado com Paulo Freire - nessa época, as obras de Paulo Freire estavam saindo em inglês, Pedagogia do oprimido, entre outros - e ele me deu a maior força. Escrevemos até um artigo 
3. Lima, Venício de; Christians, Clifford. "Paulo Freire: The Political Dimension of Dialogic Communication". Communication, v. 4, n. 1 , 1979, pp. 133-155.

4. Sader, Emir (org.). Lula e Dilma - 10 anos de governos pós-neoliberais no Brasil. São Paulo: Boitempo/FLACSO, 2013. juntos, antes de a tese ser defendida, que saiu numa revista inglesa ${ }^{3}$. A história é essa, e eu acabei ficando amigo do Paulo Freire.

$C \mathcal{E} E$ : Estamos passando por um momento de profunda reflexão, por conta de novidades trazidas pelas novas tecnologias, internet e redes sociais. Temas relacionados à vigilância (do governo dos EUA), controle (da internet), privacidade (biografias não autorizadas), censura e liberdade de expressão, entre outros, tomaram conta dos debates na sociedade atual. Estamos sabendo lidar com essas novidades?

VL: É interessante isso porque a impressão que temos é que, em qualquer momento que se fale sobre questões sociais, culturais, políticas, você está vivendo um momento de transição, de mudanças. É sempre assim. Às vezes se tem a ideia de que o processo está mais acelerado, menos acelerado. Ou se tem indicações muito evidentes de que mudanças estão ocorrendo, mas a característica de processo em transformação permanente é uma constante. E o mais interessante, eu acho, é que os estudiosos da área não desenvolveram instrumentos capazes de antecipar, às vezes, consequências dos processos de mudanças que aparecem, e acabam surpreendendo todo mundo. Estou falando isso, pensando numa experiência recente que tive, que acho emblemática dentro dessa situação. Eu fui convidado pelo Emir Sader para escrever um capítulo sobre Comunicação naquele livro que ele editou acerca dos dez anos de governos pós-neoliberais ${ }^{4}$. É uma coletânea que contempla várias áreas e, quando ele me convidou, inclusive, falei que, na minha área, o balanço é negativo, muito negativo. E ele aceitou. O livro foi lançado em maio de 2013; com um amplo leque de áreas e, cada um de nós, autores, assinou um contrato em que nos comprometíamos a participar de ao menos três lançamentos. Houve um primeiro lançamento em São Paulo, depois em Porto Alegre. O Lula compareceu nos dois, então, num certo sentido, apesar de ter uma perspectiva crítica não só no meu capítulo, mas em outros também, o livro era a celebração de um avanço, de caminhada, num sentido de avanço social. Semanas depois, aconteceram as manifestações do final de junho. A perspectiva do livro, dos lançamentos, mesmo eu que escrevi um texto crítico, o balanço geral era de um país que ia bem, que estava tudo no caminho certo, de que as coisas estavam caminhando. Havia índices de aprovação do governo e de satisfação com a presidente como nunca existiram. E, de repente, aquele negócio todo explodiu, e o que era bom passou a ser ruim, e a maioria das pessoas não esperava que aquilo acontecesse. E depois, olhando para trás, o que me chamou a atenção é que os temas escolhidos e contemplados no livro não incluem política urbana. E é interessante porque tem uma professora da USP, a Ermínia Maricato, da qual eu sou fã, que insistia sempre no chamado "inferno urbano", inviabilidade das cidades, e nós todos estávamos vendo isso, só que ninguém antecipou as manifestações. E o tema não foi nem contemplado no livro, não tem um capítulo sobre isso. Esse fato, creio, responde à sua pergunta. Há certa incapacidade de ver o que está de fato acontecendo. A posteriori, depois que as coisas acontecem, você começa a tentar explicar. Eu acho que todo período é de transformação, mas no nosso campo em 
particular, no campo da Comunicação, da mídia, nós, de fato, estamos vivendo um momento especial, a revolução digital, o surgimento da internet, as redes sociais, essa situação em que existem muito mais celulares do que a população, é fantástico! Hoje temos a possibilidade, inédita, nova na história, de uma comunicação interpessoal que não existia antes, com características completamente distintas da antiga mediação tecnológica, que é e continua sendo feita pela chamada velha mídia (rádio, televisão, jornal, revista etc.). Eu tenho falado, escrito sobre isso, e acho que precisamos ter muito cuidado para não precipitar - equivocadamente - e acreditar, como tem muita gente afirmando, que a formação e a disputa da opinião pública saiu do espaço público mediado pela velha mídia e passou para o espaço de interação possibilitado pelas redes. Eu acho que isso é um equívoco grave, muito grave. É preciso ter muito cuidado, porque certamente nós ainda não temos - como os últimos eventos revelaram - instrumentos ou capacidade para entender plenamente o que está acontecendo ou antecipar o que vai acontecer. Essas mudanças são muito recentes, estão num processo em que não conseguimos perceber a sua dimensão exata. Algumas a gente consegue. Mas outras, talvez as mais importantes, ainda não. Há algumas consequências óbvias, como a migração de leitura de jornais impressos para a internet, inviabilidade econômica e financeira de empresas que trabalham na publicação de material impresso, mas o que vai acontecer mesmo ainda não sabemos. É preciso ter muita cautela.

$C \mathcal{E} E$ : $O$ senhor afirmou em entrevista recente que a comunicação é o centro da discussão democrática. Qual a relação entre comunicação e política no mundo contemporâneo?

VL: Eu e o Juarez Guimarães acabamos de lançar um livro ${ }^{5}$, e fizemos juntos uma introdução, em que o argumento é exatamente esse, não tem como separar comunicação e política. Na verdade, você não pode ter uma teoria democrática que não contemple as questões relacionadas à comunicação no mundo contemporâneo. E você não pode também ter uma Teoria da Comunicação que não contemple as implicações e o papel central que, por exemplo, a liberdade de expressão no seu conceito histórico, grego e humanista moderno, representa na construção democrática. O que nós estamos reivindicando é que não tem como separar uma da outra; elas são constitutivamente vinculadas. A nossa intenção é mostrar que as implicações vão desembocar numa discussão sobre o que é liberdade. E uma disputa sobre o significado da liberdade, que hoje está polarizada numa discussão entre a visão liberal de liberdade e a visão republicana de liberdade. Isso está, de alguma forma, presente neste livro.

$C \mathcal{E} E$ : Como o senhor situa o Brasil em relação ao que está acontecendo nesta área em outros países como, por exemplo, a Inglaterra e a Argentina?

VL: Há cerca de um ano, quando saiu o Relatório Leveson, na Inglaterra, resultado do inquérito de mesmo nome ${ }^{6}$, sugeri pelo amigo Romário Schettino que o Centro de Estudos Barão de Itararé, em Brasília, fizesse uma publicação com a Lei de Meios da Argentina e o Relatório Leveson. O Relatório é enorme, são quatro volumes, mais de mil páginas, mas tem um sumário executivo
5. LIMA, Venício A. de; GUIMARÃES, Juarez (orgs.). Liberdade de expressão. As várias faces de um desafio. São Paulo: Paulus, 2013. (Coleção Temas de Comunicação).

6. Inquérito Leveson sobre a investigação das práticas e da cultura da imprensa do Reino Unido, cujo ponto mais polêmico é a criação de um órgão regulatório da imprensa no país. 
excelente. Recentemente incluímos também um documento da União Europeia e acertamos a publicação com a Fundação Perseu Abramo e, no início de outubro de 2013, recebi as traduções e passei o mês praticamente inteiro fazendo as revisões. No mesmo dia em que finalizei, saiu a decisão da Corte Suprema argentina, considerando a Lei de Meios constitucional. E, no dia seguinte, 30 de outubro, a rainha Elizabeth assina a Royal Charter, dando o sinal verde para a criação do novo órgão regulatório da imprensa na Inglaterra. Eu tive que me debruçar sobre esses processos, e uma das coisas que me impressiona é que a maioria dos críticos desconhece a lei argentina, o modo como foi gerada, porque é resultado de uma mobilização inédita da sociedade argentina para elaboração de uma proposta legal. A situação argentina era muito peculiar, porque havia uma legislação do tempo da ditadura militar que era muito restritiva, inclusive impedia que entidades sem fim lucrativo fossem concessionários de emissoras de rádio e televisão. Isso foi modificado por um decreto do Nestor Kirchner, mas havia um movimento, desde o fim da ditadura na argentina, em 1983, contrário à legislação da época, que reivindicava um marco regulatório para as comunicações. Além disso, a situação na Argentina era muito peculiar, porque, no processo neoliberal que aconteceu na América Latina inteira, as privatizações que aconteceram no país estimularam, de forma muito aguda, a concentração da propriedade na área. Um grupo como o Clarín, por exemplo, possui quase trezentas empresas. E quanto mais eu estudo o que aconteceu na Argentina, noto o quanto nós, brasileiros, estamos distantes da formação de um consenso nacional, costurado com a participação da sociedade civil nas suas mais diferentes manifestações. O que ocorreu na Argentina foi um envolvimento, que depois foi passando por declarações específicas de adesão, o equivalente nosso a Câmara de Vereadores, Assembleias Legislativas, entidades nacionais, sindicais as mais diversas, grupos de cooperativas, sindicatos de professores. Houve um envolvimento muito grande da universidade, foi elaborado um documento consensual a todos esses grupos, que foram os tais 21 pontos que deram origem à lei. Houve uma mobilização da sociedade argentina em torno da necessidade de uma lei democrática para a área. Quanto mais leio e estudo o que aconteceu lá, eu vejo o quanto nós ainda temos que caminhar. Porque, se isso não acontecer, levar em conta os interesses contrários, que existiam lá e que existem aqui, é muito difícil mudar o que foi assentado e confirmado - sobretudo nas ditaduras latino-americanas. Na Argentina, mais do que no Brasil, mas aqui também, se consolidou um sistema oligopolizado, excludente, de mídia, que é muito difícil de mexer por causa dos interesses. Eu acho que nós temos avançado muito nos últimos anos, mas eu poderia dar aqui vários exemplos, de como, comparativamente, nós estamos atrasados, sobretudo a partir da convocação da primeira Confecom $^{7}$, que possibilitou a mobilização em torno de sua própria realização.

7. Conferência Nacional de Comunicação, promovida pelo Governo Federal.
Nenhuma das proposições que saiu dela produziu qualquer efeito. É claro que a Argentina é outro país, tem outra cultura, são outras condições. Mas eu acho que ainda estamos muito longe, comparados com o que aconteceu por lá. 
$C \mathcal{E} E$ : Ao mesmo tempo em que as novas tecnologias trouxeram mudanças não só para os meios de comunicação como para toda a sociedade, o regulamento e a lei dos serviços de radiodifusão no Brasil estão completamente desatualizadas, têm mais de cinquenta anos. Como disciplinar tudo isso?

VL: Nós estamos nesse momento (novembro de 2013) tendo um exemplo de como é difícil regular qualquer coisa nessa área. O Marco Civil da Internet está na pauta de votação do Congresso Nacional e não se consegue um acordo para a votação. Eu não estou acompanhando detalhadamente, mas corremos um gravíssimo risco de não ter preservada a neutralidade da rede, o que significa que, se acontecer, talvez essa seja a maior ameaça à liberdade de expressão hoje no Brasil, porque existirão condições diferentes de acesso à circulação na rede. Quem tiver mais volume e pagar diferenciadamente, vai ter acesso proporcional ao que pagar. Isso é uma coisa que interessa, sobretudo, às grandes empresas que oferecem o serviço. Mas não é só isso. Porque não adianta ter um marco regulatório que garanta a neutralidade da rede se não tiver uma infraestrutura de banda larga que não seja privatizada também e que seja tratada exclusivamente como mais uma mercadoria. E tudo indica que nós estamos caminhando exatamente para isso. Infelizmente, nesse governo, estou me referindo ao governo da presidente Dilma Rousseff e do ministro Paulo Bernardo, tudo indica que a proposta original de se ter uma empresa controlada pelo Estado, que pudesse universalizar uma banda larga de qualidade para a população em geral, não vingará. Temos então um exemplo do tipo de questão que está envolvida e das dificuldades de se regular democraticamente o mercado de mídia. Aliás, aqui se manifesta uma questão interessante: a crise de representação que existe no Brasil em relação aos parlamentos. O cientista político Wanderlei Guilherme dos Santos fala nisso, que a sociedade civil se organiza, é representada no sindicato, mas é sub-representada no parlamento. O presidente da Câmara dos Deputados convida o representante das teles, o representante da Rede Globo, o relator do projeto, alguns líderes partidários para um jantar na casa dele e o acerto é feito ali, com a sub-representação do principal interessado. Infelizmente, nós temos de fato uma crise de representação, de sub-representação do interesse público, do conjunto da população nas decisões do Congresso Nacional.

$C \mathcal{E} E$ : Esse é um dos principais motivos para não termos uma regulação de mídia no Brasil?

VL: Não temos porque existe um círculo vicioso. Temos um sistema de mídia oligopolizado, que é corruptor da opinião pública, porque privatiza o acesso e exclui do debate público a maioria da população. Com isso, colabora para esse desequilíbrio na representação da sociedade civil no parlamento; boa parte dos parlamentares, historicamente eleitos, está direta ou indiretamente envolvida com as concessões de radiodifusão e, portanto, com os interesses dos grandes grupos, porque são a eles afiliados ou diretamente controladores de concessões. E isso se torna um círculo vicioso, porque os interesses privados dos parlamentares coincidem muitas vezes com os interesses dos grandes grupos, e isso realimenta 
um sistema que é excludente, oligopolizado, e impede que se altere um processo que beneficia quem já está nele. É um negócio impressionante. E esse círculo vicioso não é quebrado. Isso aconteceu no processo Constituinte de 1987-88, não é novidade no Brasil. É um processo que vem ocorrendo já há muito tempo e não se consegue quebrá-lo, rompê-lo. Nós celebramos recentemente os 25 anos da Constituição, e o capítulo V do título VIII da Comunicação Social ${ }^{8}$ praticamente não foi regulamentado. Existe, inclusive, uma ADO, Ação Direta de Inconstitucionalidade por Omissão, que o professor Fábio Konder Comparato elaborou e está no Supremo Tribunal Federal, pedindo que interceda para que o Congresso regule as normas da Constituição que estão lá e não são regulamentadas.

\section{$C \mathcal{E} E$ : Por que a regulação dos meios de comunicação não é debatida pela grande mídia?}

VL: A mídia brasileira não discute a si mesma. Interessante, porque no processo argentino, por exemplo, como o domínio do grupo Clarín era tão grande, eles fizeram inclusive campanhas, usando argumentos que são repetidos aqui. Os mesmos argumentos, o do controle remoto, o de que as novas tecnologias fazem com que toda discussão sobre propriedade cruzada já não faça sentido, argumento que inclusive o ministro das Comunicações tem repetido aqui. A mesma coisa, só que no Brasil não se faz a discussão, não se faz o debate publicamente. Temos avançado porque as formas alternativas de acesso a alguma forma de espaço público - sites, blogs, redes etc. - têm possibilitado um pouco isso.

\section{$C \mathcal{E}^{\circ} E$ : $O$ que a regulação da mídia vai trazer de benefícios para o cidadão comum?}

VL: Essa é uma questão muito interessante. Recentemente escrevi uma introdução para o livro do Pedrinho Guareschi ${ }^{9}$ em que falo exatamente isso. Uma das dificuldades daqueles que lutam pela liberdade de expressão é traduzir para o conjunto da população essas questões da comunicação de tal forma que as pessoas compreendam que o direito à comunicação, o acesso ao debate público etc. é algo que tem a ver com o cotidiano de cada um de nós, que nos afeta no dia a dia. É muito difícil fazer isso, mas existem várias formas de mostrar esses benefícios. Vou começar com um exemplo simples. Está na Constituição, no artigo 221, que a programação de rádio e televisão deve se orientar por alguns princípios. Um deles é a questão da produção regional. De priorizar a produção regional, feita por cultura nacional, educativa, e a produção independente. Imagine, num país do tamanho do nosso, regularizar e disciplinar, por lei, um princípio como

8. Disponível em: <www. senado.gov.br/atividade/ conselho/atribuicoes. asp? $=$ CCS $>$. Acesso em: 23 jan. 2014.

9. GUARESCHI, Pedrinho A. $O$ direito humano à comunicação. Pela democratização da mídia. Petrópolis: Vozes, 2013. esse. Em cada estado ou região brasileira, ter estímulo para produção cultural, jornalística, educativa, local, feita por produção independente local. Isso tem repercussões na formação profissional, no mercado de trabalho, na economia, porque, por exemplo, a produção independente vai gerar emprego, terá uma cadeia produtiva que será criada, incentivada. Isso terá efeito em longo prazo até na identidade das pessoas, que vão se ver representadas na programação de rádio e televisão. Isso hoje só acontece em relação aos excluídos, aos pobres, aos 
miseráveis, que são motivo de chacota nos programas policiais locais. Hoje há uma consciência muito maior em relação a isso, mas as implicações da regulação, do que já está na Constituição, seriam imensas. Imagine, por exemplo, a questão da programação dirigida às crianças em relação, por exemplo, à alimentação infantil. Há algum tempo houve uma regulação da Agência Nacional de Vigilância Sanitária (Anvisa) que tentava disciplinar a propaganda de alimentos que tinham excesso de gordura e açúcar etc., e a Associação brasileira de empresas produtoras de alimentos entrou na Justiça, alegando que aquilo a Anvisa não podia regulamentar, porque era norma constitucional, que tinha que ser regulamentada por lei complementar. E ganhou. Na Lei de Meios argentina, por exemplo, criou-se inclusive um organismo para cuidar especificamente dessa questão, como existe no mundo inteiro. Isso é o que nós não conseguimos fazer: uma discussão para mostrar a quem tem filho pequeno questões desse tipo. A questão do parágrafo $\mathrm{V}$, do artigo 220, que fala que não pode ter oligopólio nem monopólio, imagine que, também na lei argentina, há a reserva de 33\% das concessões de rádios e televisão para sindicatos, universidades, organizações de povos originários, cooperativas, igrejas. Uma alteração desse tipo muda não só o cenário da comunicação, mas muda o mercado de trabalho, as profissões, a formação profissional, muda muita coisa na sociedade. No entanto, isso é muito difícil de as pessoas perceberem. Sobretudo quando se naturaliza um processo como se ele fosse único e não se discutem as alternativas para um processo que já está aí há muito tempo. Então, os benefícios para a população são imensos, só que muitas vezes é difícil mostrá-los.

\section{$C \mathcal{E} E$ : Qual é o papel de entidades como os Conselhos Regional e Municipal de Comunicação Social ou o Fórum Nacional pela Democratização da Comu- nicação (FNDC)?}

VL: Eu me sinto um pouco Dom Quixote com esses Conselhos, brigando contra os moinhos de vento. Tenho falado há muitos anos que, do ponto de vista de estratégia política para mobilizar setores mais amplos da sociedade para a questão da liberdade de expressão, entre outras, devíamos complementar a disputa, em nível nacional, com o que pudesse ser disputado em nível regional e local. Porque é mais concreto, mais objetivo. Quando a Constituição de 1988 criou o Conselho de Comunicação Social como um órgão auxiliar do Congresso (essa não era a proposta original, da emenda popular. Explico tudo no meu livro ${ }^{10}$, publicado pelo Fórum Nacional pela Democratização da Comunicação) pelo princípio da simetria, as Constituições Estaduais, quando se adaptaram à nova Constituição, muitas criaram capítulos sobre a Comunicação Social. Além de um capítulo sobre Comunicação Social, foram criados também Conselhos Estaduais de Comunicação em nove estados e no Distrito Federal, tendo como referência o Conselho criado no artigo 224. Somente a Bahia, há pouco mais de um ano, instalou e colocou em funcionamento um Conselho Estadual de Comunicação como órgão auxiliar do Poder Executivo Estadual. Mal ou bem, ele está funcionando. Houve também tentativa de criação no Rio Grande do Sul, em Alagoas
10. LIMA, Venício A. de. Conselhos de comunicação social. A interdição de um instrumento da democracia participativa. Brasília: FNDC, 2013. 
e em Minas Gerais. Mas são processos, cada um com a sua peculiaridade, que não funcionam. Esses Conselhos seriam apenas órgãos auxiliares, dependendo das propostas, do Poder Executivo, ou das Assembleias Legislativas. Mas qual seria a grande conquista desses Conselhos? Eles institucionalizariam um espaço regional, estadual, para discussão das questões de comunicação. Nós não temos fóruns institucionalizados de debate dessa questão como política pública, que interessa a todo mundo. E esses Conselhos Estaduais poderiam influir, opinar, propor, interferir na formulação dos Planos Estaduais de Comunicação, na aplicação dos recursos estaduais para a área de mídia. E poderia haver interferência na alocação desses recursos, aliás, dentro das prioridades definidas constitucionalmente, para multiplicar as vozes que são ouvidas no espaço público de cada estado. Favorecer as rádios e tevês comunitárias, os jornais alternativos, os jornais de bairro, as iniciativas populares, poderia ter ao menos um espaço de debate, de discussão, de reflexão sobre essas coisas. Porque uma das características da Constituição de 1988 é a descentralização administrativa e o aumento da participação popular, para a formulação, acompanhamento, avaliação de políticas públicas. E a comunicação é uma dessas áreas, só que essas coisas não acontecem. Mas seria um caminho, inclusive do ponto de vista de estratégia política. Não é uma questão fácil, porque os interesses que ficam às vezes evidentes em nível nacional se reproduzem em nível regional, estadual e local.

\section{REFERÊNCIAS}

GUARESCHI, Pedrinho A. O direito humano à comunicação. Pela democratização da mídia. Petrópolis: Vozes, 2013.

LIMA, Venício A. de; CHRISTIANS, Clifford. Paulo Freire: The Political Dimension of Dialogic Communication. Communication, v. 4, n. 1, 1979.

LIMA, Venício A. de; GUIMARÃES, Juarez (orgs.). Liberdade de expressão. As várias faces de um desafio. São Paulo: Paulus, 2013. (Coleção Temas de Comunicação).

LIMA, Venício A. de. Comunicação e cultura: as ideias de Paulo Freire. 2. ed. rev. Brasília: Editora da Universidade de Brasília/Fundação Perseu Abramo, 2011.

. Conselhos de comunicação social. A interdição de um instrumento da democracia participativa. Brasília: FNDC, 2013.

SADER, Emir (org.). Lula e Dilma - 10 anos de governos pós-neoliberais no Brasil. São Paulo: Boitempo/FLACSO, 2013. 